\title{
POSSIBILITY TO USE MOBILE LEARNING TO PROMOTE WORLD HERITAGE SITE PRESERVATION AWARENESS IN LUANG PRABANG, LAO PDR: A READINESS STUDY
}

\author{
Y. S. Poong ${ }^{\mathrm{a}, *}$, S. Yamaguchi ${ }^{\mathrm{b}}$, J. Takada $^{\mathrm{c}}$ \\ Graduate School of International Development Engineering, Tokyo Institute of Technology, Tokyo, Japan \\ ayspoong@ap.ide.titech.ac.jp, byamaguchi@gsic.titech.ac.jp, ${ }^{\mathrm{c}}$ takada@ide.titech.ac.jp
}

KEY WORDS: Mobile Learning, World Heritage Site, Preservation, Lao PDR, Technology Adoption

\begin{abstract}
:
This paper elucidates the current state of mobile technology readiness among young adults in higher education institution based on surveys and interviews. Although Lao PDR is ranked as low category in the ICT Index by International Telecommunication Union (ITU), findings show that there exists high level of readiness among the young adults. Recommendations for future research are developed to guide the development of mobile learning application with the aim to promote World Heritage Site preservation awareness.
\end{abstract}

\section{INTRODUCTION}

Rapid development of Luang Prabang World Heritage town has triggered an urgent call for preservation (UNESCO, 2008). Since 2003, ICT tools, such as heritage database and geographic information systems have been developed to assist the management of World Heritage Site in the Department of World Heritage Site of Luang Prabang (DPL). As a result, positive outcomes observed from the project implementation include increased management efficiency, increased confidence on ICT use among staff members in DPL, better understanding of information sharing concept and collaboration among local departments (Yamaguchi, et. al., 2006).

Acknowledging the potential advantages of ICT, this paper presents an initial exploration of mobile learning perception, as part of the progressive investigation in promoting World Heritage Site preservation awareness for the local community in Luang Prabang. This study fits under the research project framework of sustainable management of World Heritage Site using ICT. However, given the rank of 121 st over 152 countries in ICT development index by ITU (2011), the question of whether the concept of "mobile learning" is established among the local community remains uncertain.

Given this background, an investigation was carried out to fill in the knowledge gap. First, this paper presents the assessment of technology readiness among the higher education students in Luang Prabang, from the following three points: 1) the computing devices owned; 2) connectivity options; and 3) devices used for common digital activities. As literature survey reveals, first adopter of new innovations is frequently from the younger generation (Rogers, 1983). Therefore, this study samples young adults from higher education institutions as the target respondents. The findings of this aspect would shed light on current state of mobile phone use, which guides the feasibility of mobile learning implementation. Past literatures indicate that understanding potential users' perception is vital for technology acceptance. There are many factors affecting adoption of technology. However, since there are limited prior studies available related to mobile learning acceptance, this study, therefore, postulates eight common determinants that would affect intention to use mobile learning among young adults in Luang Prabang. This is achieved by testing eight hypotheses using correlation analysis on data obtained from questionnaire survey. Finally, interviews were conducted to supplement the findings from the survey.

It is foreseen that the development of mobile learning application will further promote the perception of local community on the efforts done in preserving heritage buildings. In particular, there are many activities carried out by DPL, including the development of heritage buildings database and VR panorama technique to document inventory buildings. In addition, international agencies, such as UNESCO and ICOMOS, have been involving in fundamental preservation efforts together with local experts, such as building and architecture monitoring and documentation. The role of mobile learning, hence, is positioned as an education agent to convey such efforts in heritage preservation to achieve shared understanding among the local communities for long term benefit.

\section{MOBILE LEARNING COMPLEXITIES}

With the aim to increase sense of importance on heritage site preservation through promoting preservation awareness, mobile learning is defined in this context as "acquisition of any knowledge and skill through the use of mobile technology, anywhere, anytime that results in an alteration in behavior" (Geddes, 2004, p.1).

\subsection{Mobile Learning in Developing Countries}

Technology leapfrogging in developing countries encourages the use of mobile phone in various ways, including learning. This is evidenced from the workshops and conferences held by international development agencies, such as mobile learning week in 2013 and mobile learning workshop in 2005 by UNESCO to discuss about mobile learning implementation policies. Despite this, clear policies to implement mobile learning in developing countries are still in the stage of 
discussion, depicting the high degree of challenges of implementation compared to developed countries. Nevertheless, cases of mobile learning implementation are in place, for instance, interactive mobile game to increase HIV/AIDS prevention awareness in India (Freedom HIV/AIDS, 2008) and the kickoff of rural teacher training support through mobile learning in Pakistan (UNESCO, 2012).

\subsection{Mobile Learning Challenges in Lao PDR}

In order to implement mobile learning, certain level of infrastructure is needed, for example, stable electricity supply, sufficient mobile network coverage, and acceptable mobile broadband performance. Being a least developed country, Lao PDR is still facing frequent electricity outages although its improvement is evident. In addition, the country has introduced high speed mobile broadband in recent years, with coverage within main cities. Given that mobile broadband is still relatively new in this context, the question remains on whether the community has put the technology into practice. In 2011, Lao PDR was upgraded by World Bank from low income economy to lower-middle income economy nation (average income USD 1,006 to USD 3,975) (World Bank, 2011). Although the cost of basic mobile phone is less expensive in comparison to laptop or desktop PC, this may not be the case for smartphones. In contrast with basic normal mobile phones, smartphones has the capability to install and execute innovative applications. In addition to the mobile phone itself, users are required to pay for service cost such as SMS, voice call, and mobile broadband. Given the lower-middle income population, the level of smartphone diffusion is still unknown in Lao context, let alone the rate of use and the ability for local people to identify innovative mobile applications.

\subsection{Theories of Acceptance and Use of Technology}

Performance expectancy, effort expectancy, and social influence are posited to affect an individual's behavioral intention to use of IT, which in turn affect use behavior. Performance expectancy captures individual's belief that "the system will help him or her to attain gains in job performance" (Venkatesh et. al., 2003, p.447). Effort expectancy is "the degree of ease associated with the use of the system" (Venkatesh et. al., 2003, p.450), and social influence is the belief that whether or not people who is important to the potential user agrees with potential user's adoption of the technology. Facilitating conditions assess potential user's perception on the existence of organizational and technical infrastructure support towards the use of technology. Facilitating condition is another variable posited to influence use behavior.

Past findings show that there are gender differences in task handling (Minton \& Schneider, 1980). In addition, empirical study found age differences in the context of technology adoption and task attitude (Hall \& Mansfield, 1995, Morris \& Venkatesh, 2000). Thus, the theory also postulates that gender moderates performance expectancy, effort expectancy, and social influence on user's behavioral intention to use technology.

Rogers (1983) devised five innovation attributes that influence its adoption, namely: relative advantage, compatibility, complexity, trialability, and observability. Relative advantage refers to the perception that an innovation is better or worse than the succeeded innovation. Compatibility is the degree of an innovation is seen as fit with the experience, culture, and beliefs of potential adopters. Complexity is defined as "the degree to which an innovation is perceived as relatively difficult to understand and use" (Rogers, 1983, p. 230). Trialability refers to the ability of an innovation to be experimented by potential adopters before being fully adopted. Finally, observability is the visibility of the result of using an innovation. Rogers (1983) asserts that innovations with these attributes are more favourably accepted than those do not.

Davis (1989) hypothesizes that an individual's behavioral intention to use a technology is determined by his or her attitude towards the use of the technology. Attitude refers to "the degree of evaluative affect that an individual associates with using the target system in his or her job" (Davis, 1989, p. 320). Attitude is in turn, determined by perceived usefulness and perceived ease of use. Perceived usefulness is "the degree to which an individual believes that using a particular system would enhance his or her job performance" (Davis, 1989, p. 320). Perceived ease of use is defined as "the degree to which an individual believes that using a particular system would be free of physical and mental effort". (Davis, 1989, p. 320)

It was found that existing theoretical models has limitation in capturing variables suited to Luang Prabang context. For instance, Luang Prabang is still facing issue of basic facility supply. Environment supporting variables for mobile learning use needs to be considered in this study. In addition, the lack of focus on target respondents from the least developed countries raised the question on the applicability of existing theoretical models. Hence, based on the literature reviews and considering the local context, this study postulates that:

H1: There is a relationship between perceived usefulness and behavioral intention to use mobile learning among young adults in Luang Prabang

$\mathrm{H} 2$ : There is a relationship between perceived ease of use and behavioral intention to use mobile learning among young adults in Luang Prabang.

H3: There is a relationship between social influence and behavioral intention to use mobile learning among young adults in Luang Prabang.

H4: There is a relationship between personal innovativeness and behavioral intention to use mobile learning among young adults in Luang Prabang

H5: There is a relationship between self-efficacy and behavioral intention to use mobile learning among young adults in Luang Prabang

H6: There is a relationship between perceived enjoyment and behavioral intention to use mobile learning among young adults in Luang Prabang

H7: There is a relationship between perceived price and behavioral intention to use mobile learning among young adults in Luang Prabang

H8: There is a relationship between perceived facilitating resources and behavioral intention to use mobile learning among young adults in Luang Prabang

There is no positive or negative relationship being specified in the hypotheses since current study attempts to explore the 
possible relationship between the independent variables and intention to use mobile learning. Therefore, a two-tailed correlation statistical analysis method is adopted. Further explanation is provided in the following sections.

\section{METHODOLOGY}

Acknowledging the uncertainties identified in preceding section, we adopted a two-phase approach to assess the level of technology readiness to adopt mobile learning. Data was empirically collected from two higher educational institutions in Luang Prabang, namely, Souphanouvong University (SU) and National Law College (NLC), in March 2012. Both SU and NLC are public higher education institutions, with SU as one of the four national universities in Lao PDR and NLC being under the Ministry of Justice. SU and NLC were established in Luang Prabang in 2003 and 2004 respectively.

\subsection{Phase 1: Survey}

In phase 1, survey questionnaire, which consists of questions on respondents' demographic and the profile of mobile phone owned by the respondents, were administered. The questions on use of computing devices, including mobile phone, on nine digital activities were also asked. This is to evaluate mobile phone use behaviour in relation to other computing devices. In addition, respondents were requested to rate their perceptions on the 5-point Likert scale, in which scale 1 represents "strongest agreement" and scale 5 designate "strongest disagreement". The questionnaire was translated into Lao language and was further modified based on the feedback from the DPL to suit the local context. The survey was administered in the presence of DPL professionals in the institutions on March 2012. Prior to the distribution of the questionnaires, the purpose of the research was explained to the students in Lao language. A total of 484 copies of questionnaires were distributed, 200 copies and 284 copies to SU and NLC respectively.

\subsection{Phase 2: Interview}

In the second phase of this research, the preliminary findings were presented to interviewees to stimulate discussion about the possibility of using mobile learning to promote heritage site preservation awareness. The interviewed questions include the perspective of mobile phone use, suitability of using mobile phone to promote heritage site awareness, application design recommendations, facility support for learning using mobile phone, and gender differences. Interviews were conducted in November 2012, and findings of the interviews were synthesized based on content analysis methodology.

\section{RESULTS}

\subsection{Survey Respondents Demographic}

Of the total 484 distributed questionnaire, a total of 443 copies, with 199 copies and 244 copies from SU and NLC respectively, were returned, resulting in $91.5 \%$ return rate. Inspection on returned questionnaire was performed to ensure validity. Questionnaires with high number of unanswered responses are discarded (including total unanswered). Also, questionnaires with answers not adhering to answering requirements were also discarded from further analysis. The omitted questionnaire comprise of $17.6 \%$ of the returned questionnaires. Finally, a total of 365 questionnaires were deemed suitable for analysis.
Respondents are mainly composed of male (61.4\%) than female (34.5\%). This is almost identical to Lao national demographic, in which male enrollment into tertiary education dominates female according to the United Nations Statistic Division (United Nations, 2010). As shown in Table 4.1, Majority of the respondents is around 20 to 24 years old (70.4\%), and is studying in Year Three $(21.1 \%)$ and Year Four $(56.4 \%)$ in the institutions. Mixed distribution of allowance received per month is observed among the respondents. Those who received more than 100,000 Lao Kip (approximately 13USD) per month $(26.6 \%)$ represents the greatest number than other categories. Ironically, the next category is followed by those who received the least, less than 20,000 Lao Kip per month (22.2\%). Mixed responses show that the following analysis represents feedback from young people with diverse income level.

\subsection{Mobile Phone Demographic}

4.2.1 Most common device owned by student is mobile phone, followed by laptop: The number of devices owned by respondents reveal interesting trend. As shown in Figure 1, given the multiple response options of mobile phone, tablet, laptop and personal computer (PC), a total of 587 (161.7\%) cases were reported. This means respondents in this study own between 1 to 2 devices at the same time. The device that most owned by respondents is mobile phone $(n=358)$, followed by laptop $(n=188)$, PC $(n=29)$ and tablet $(n=12)$. The figures conform to the trend of mobile phone ownership in several other developing countries and depict the potential of using mobile phone as a tool to implement innovative ICT application.

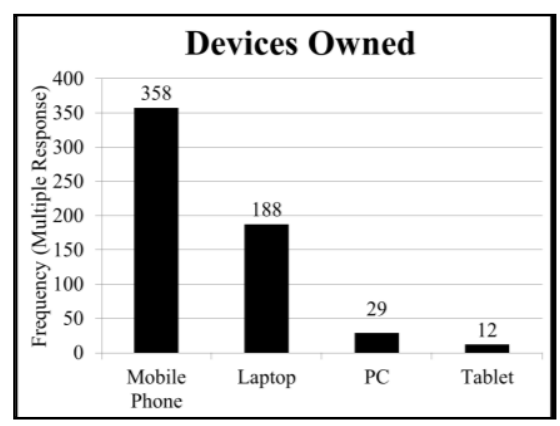

Figure 1. Devices owned by respondents (Total multiple responses $=587$ out of total sample size $=365$ )

4.2.2 Smartphone is popular among university students with 3G and WiFi functionality: As shown in Figure 2, data analysis reveals that $179(66.8 \%)$ of the respondents' mobile phone is a smartphone.

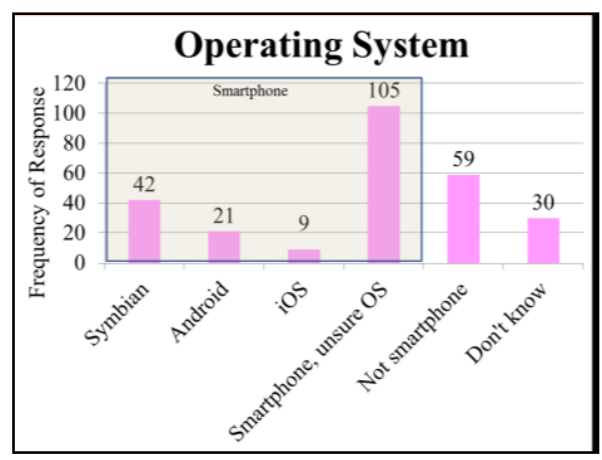

Figure 2. Operating system of owned mobile phones (Total responses $=358$, no response $=92$ ) 
As shown in Figure 3, connectivity wise, the number of respondents who owned a $3 \mathrm{G}$-enabled mobile device $(\mathrm{n}=149$, $28.5 \%$ ) is greater than those who owned a WiFi-enabled mobile device $(\mathrm{n}=77,14.7 \%)$. The high number of Internet-ready smartphones owned by the respondents suggests that more varieties of innovative applications could be developed.

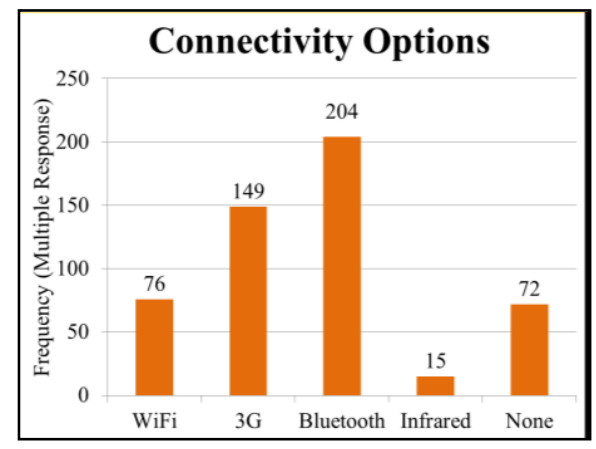

Figure 3. Connectivity options (Total multiple responses $=451$ out of total mobile phone owners $=358$ )

\subsubsection{Laptop is the main device used for digital} activities, followed by mobile phone: The survey also explored devices used for various digital activities. Analysis shows that laptop is the most used device, followed by mobile device. Specifically, laptop is used mainly for searching information $(\mathrm{n}=231,55.8 \%)$, learning new knowledge $(\mathrm{n}=231,55.8 \%)$, email $(n=223,53.3 \%)$, watching video $(n=220,52.8 \%)$, engaging in social networking sites $(\mathrm{n}=203,51.3 \%)$, playing game $(\mathrm{n}=178,41.9 \%)$, and reading news $(\mathrm{n}=134,36.7 \%)$. On the other hand, mobile device is used mainly in chatting $(n=230$, $53.4 \%)$ and listening to music $(n=213,45.4 \%)$.

\subsection{Perceptions on Mobile Learning}

Correlation analysis was used to test the relationship between students' perception on mobile learning and their intention to use mobile learning. Table 1 shows the correlation analysis results. At a statistically significance of 0.01 level, there is enough evidence that relationship exists between hypothesized independent variables and intention to use mobile learning.

\begin{tabular}{|l|r|}
\hline Independent Variables & Intention to Use \\
\hline Personal Innovativeness & $0.309^{* *}$ \\
\hline Social Influence & $0.161^{* *}$ \\
\hline Self-Efficacy & $0.193^{* *}$ \\
\hline Perceived Ease of Use & $0.355^{* *}$ \\
\hline Perceived Enjoyment & $0.469^{* *}$ \\
\hline Perceived Usefulness & $0.371^{* *}$ \\
\hline Perceived Price & $0.179^{* *}$ \\
\hline Perceived Facilitating Resources & $0.451^{* *}$ \\
\hline \multicolumn{2}{|c|}{ ** Correlation is significant at the 0.01 level (2-tailed). }
\end{tabular}

Table 1. Pearson Correlation Analysis

In addition, the two-tailed correlation test shows that the independent variables affect intention to use mobile learning in a positive direction, albeit varying correlation degree. As the analysis result shows, the strongest correlation with intention to use mobile learning is perceived enjoyment, followed by perceived facilitating resources, and perceived usefulness. The weakest correlation is social influence. Discussion on these findings will be provided in the next section.

\subsection{Interview Findings}

Interview was conducted in November 2012 in Luang Prabang. Despite attempts to invite volunteer respondents, only four young adults agreed to be voluntarily interviewed. The interviewees consisted of two males and two females, which include a high school student, a year two, a final year, and fresh graduate of university students. Two interviewees possess basic mobile phones while another two interviewees are active smartphone users.

4.4.1 Sociability as the key factor influencing self-efficacy, exposure to information technology subjects: Interview findings show that female young adults interact with mobile phones more frequent than the males do. Female mobile phone use behavior reveals that female often use mobile phones to take photos and share them over the internet. This has led to more familiarity with mobile phone functions. In addition, interview result shows that female appears to have more time to learn technology, such as examining the ways to use mobile phones and photo editing software. An important finding is that female respondents often shares news and knowledge with each other actively. This is often useful when female faces difficulties in using new technology. They would turn to peers, regardless of gender, to ask for assistance to solve any complications when using technologies, such as mobile phone. This has led to the small difference between female and male self-efficacy dimension. Students in Luang Prabang are taught about information technology subjects since secondary school level, such as computer hardware and software, both in theory and practical aspect. Moreover, university students are exposed to a level deeper based on their major. For example, programming is taught in engineering and computing faculties, while students in business faculties learn office applications. Education syllabus is believed to contribute to young adults' ability in using computing technologies.

4.4.2 Choice of mobile application used affects ease of use perception: On the other hand, males are interested in learning information technologies that provide direct advantage to them, such as applications that are beneficial to homework or job. Another distinction between male and female is the choice of mobile applications used. Interview found that male young adults are heavy and new applications, such as watching videos, using GPS based application, while females use light applications, such as photo editor and chatting applications. This has led to the difference of ease of use perceptions on mobile learning.

4.4.3 Trend, rich functionality as motivator and financial feasibility as the barrier to adopt smartphones: Individual interviewers acknowledged the strong influence of trend for themselves and for the friends to switch to smartphones. Interview reveals that the ownership of famous smartphone brand appears to be a fashion among the young adults. In addition, smartphone users appreciate the variety of available applications, especially social application and communication applications that uses internet data. Interviewees who are nonsmartphone users possess the intention to change to smartphone due to the ease of information searching functionality. However, the factor that deters the use of smartphone is affordability.

4.4.4 Higher expectation on network coverage and meaningful heritage information from mobile learning: Interviewees, regardless of smartphone and non-smartphone 
users, expressed their dissatisfaction on the stability and coverage of network signals. Within Luang Prabang town, there is issue of $3 \mathrm{G}$ speed stability. On the other hand, when one moves slightly away from Luang Prabang town, then there is no $3 \mathrm{G}$ signal available. This issue is quoted as possible hindrance on the use of mobile learning by interviewees. In order to attract young adults to use mobile phone for learning the heritage site, interviewees emphasized the need to incorporate mixed interaction within the application and also Lao language support. Content wise, rules and regulation, culture, and information on how the heritage town is changing are very much appreciated. This arises from the fact that there is limited access to information related to heritage site. One of the examples cited is about school teachers giving assignment to students to look for heritage site information. The availability of such information on mobile phone would enhance students' learning experience.

4.4.5 Distinct viewpoints between basic mobile phone and smartphone adopters: Finally, there is a distinct viewpoint on mobile phone use between smartphone and non-smartphone users. In the independent interview, both interviewees who are non-smartphone users coincidentally voiced their concern on the negative impact to the image of Luang Prabang by taking and uploading inappropriate pictures to the internet via mobile phones. On the other hand, there is no such concern mentioned by smartphone users.

\section{DISCUSSION}

\subsection{General Discussion}

The discussion section covers the major findings from the questionnaire on target users' mobile phone ownership demographics, perceptions, and interview. In particular, findings of interview is discussed along the aspect of 1) eagerness to know how to preserve the World Heritage Site, 2) social influence impact, 3) gender distinctions on mobile learning use perceptions, and 4) compatibility factor by adapting Lao language interface.

Consistent with theory of technology acceptance, there exists acceptable level of facilitating condition for the possibility to implement and use mobile learning. This is evident based on the findings that 1) mobile phone ownership exceeds other computing devices, 2) the reported rate of smartphones exceed basic phones, and 3) mobile phone is the second most used device to perform the nine common digital activities.

With regard to the possibility of using mobile phone in promoting heritage site preservation awareness, this study reveals that respondents do appreciate the use of mobile learning application for the said purpose. This notion is also consistent with the perceived usefulness factor in the theory of technology acceptance. However, simply providing heritage information may not be sufficient to stimulate active use of the application. More detailed ways to promote awareness are suggested by the respondents, conforming to perceived enjoyment and personal innovativeness perceptions. This shows the eagerness of the young adults to know more about how to preserve their heritage town by means of convenient information access.

Social influence does play significant role in the adoption of smartphones, which may serve as a catalyst for mobile learning. Although social influence appears as the lowest relationship with intention to use mobile learning, we suspect that social influence does not directly affect the use of mobile learning. Instead, the relationship between social influence and behavioural intention to use may be mediated by some other variables (Raaij and Schepers, 2008). As the interview findings show, trend and usefulness of smartphones demonstrated by first adopters seems to affect non-adopters intention to adopt smartphones among the young adults. Hence, perceived usefulness may be a possible mediator warrant for further investigation.

Finally, the interview puts focus on gender access to mobile technology. This was motivated by the curiosity whether females have less access to mobile technology compared to males in developing countries, and an intention to understand universal access to heritage preservation application to be developed in the future. As depicted in the reviewed theoretical framework, one of the important moderators of acceptance is gender. Interestingly, females tend to have more positive outlook on mobile technology than the males in this study. One of the possible explanations could be related to Laos's social structure and the demographic background of male students from the rural area studying in the town of Luang Prabang.

In fact, another often cited factor for designing mobile learning application during the interview is the inclusion of Lao language. The limited applications in Lao language may be the reason that prompted such response from the respondents. However, there are two theoretical explanations underpinning this. First, with the use of Lao language, it caters for the target users directly. This is in accordance to Roger's (1983) Diffusion of Innovation theory, where one of the factors determining the rate of an innovation is "compatibility", which refers to the degree to which an innovation is perceived as being consistent with the existing values, past experiences, and needs of potential adopters. Second, with the use of Lao language, this can facilitate potential users' self-efficacy and perceived ease of use in using mobile phone for learning. This notion is consistent with the theory of technology acceptance reviewed in this study.

\subsection{Practice Recommendations}

Several practice recommendations for mobile learning application development are provided based on the findings.

\subsubsection{When developing mobile learning to preserve} heritage site, consider incorporating social element within the implementation framework. Social elements could be designed within the mobile application, for instance, the inclusion of comment or sharing functionality. Also, implementation initiatives could also take advantage of the role of different social actors to promote the use of mobile learning. For example, teachers could play an important role to encourage students' use of mobile learning. Requiring students to use mobile phone to look for heritage site information could be one of the specific examples.

5.2.2 Provide variety of interaction mode to enhance both male and female users to use mobile learning. Instead of developing a read-only application, quiz, animation-based, or other innovative interactions with the mobile phone for learning are needed to stimulate motivation to use mobile phone for learning. In addition, valuable contents could increase potential users' intention to adopt mobile learning. Hence, proper content should be designed into the application. 
5.2.3 Suggest telecommunication operators to consider the issue of telecommunication network quality. The increasing number of smartphone users may inevitably putting pressure on the network bandwidth. Therefore, telecommunication operators are recommended to adopt effective network strategy that could ensure acceptable quality of service.

5.2.4 Investigate sustainable factors for mobile learning implementation from the development viewpoint. Given relatively lower level of ICT readiness than developed nations, the understanding of sustainable factors from least developing country perspective is required for continuous development and for ensuring the effectiveness of mobile learning as an educational tool. Possible areas to be examined include implementation policy and application development methodology.

\subsection{Limitations and Future Research}

The findings on this study should be interpreted in light of its limitations. As an explorative study, current research draws from student sample, which calls for caution on data generalizability. The total of 365 valid responses represents 5\% of the student population from the two local higher education institutions.

As this research project progresses, an imminent task is to identify suitable and appropriate contents to be included into the mobile learning application. This is achieved through close discussion with DPL members in the local site. Among the possible contents are rules and regulations based on the Safeguarding and Valorisation Plan (PSMV). As an educational tool for heritage site preservation, information on efforts of preservation will also be considered. This includes building architecture documentation techniques applied in the local site. Also the understanding of roles of international agencies, such as UNESCO and ICOMOS, on monitoring and preservation of heritage is deemed to be important learning content in order to promote globalized awareness in heritage preservation. Nevertheless, presenting learning contents and information in a dynamic device that has limited screen viewing estate poses extra challenges. Among others, interaction mode, persuasiveness and effectiveness of raising heritage preservation awareness through mobile learning application form an integral part of study in the future.

\section{CONCLUSION}

In summary, this study implies a high possibility to promote World Heritage Site preservation awareness through the use of mobile learning in Luang Prabang. Although it is not yet directly related to the implementation aspect, current study has provided empirical exploration on the readiness perspective to improve understanding of utilizing mobile technology in heritage preservation education on the otherwise scarce literature.

\section{REFERENCES}

Davis, F. 1989. Perceived usefulness, perceived ease of use, and user acceptance of information technology. MIS Quarterly, 13(3),319-340.

Freedom HIV/AIDS, 2008. Retrieved September $28^{\text {th }}, 2012$, from http://www.freedomhivaids.in/
Geddes, S. J., 2004. Mobile learning in the $21^{\text {st }}$ Century: Benefit for Learners. Knowledge Tree E-Journal: An Ejournal of Flexible learning in VET, 30 (3), $1-13$.

Hall, D., and Mansfield, R., 1995. Relationships of age and seniority with career variables of engineers and scientists. Journal of Applied Psychology, 60(2), 201 - 210.

ITU., 2011. Measuring the information society 2011. Geneva, Switzerland.

Minton, H.L., and Schneider, F.W., 1980. Differential Psychology, Waveland Press, Prospect Heights, IL.

Morris, M.G., and Venkatesh, V., 2000. Age differences in technology adoption decisions: Implications for a changing workforce. Personnel Psychology, 53(2), 375 - 403.

Raaij, E.M.V., and Schepers, J.J.L. 2008. The acceptance and use of a virtual learning environment in China. Computers \& Education, 50, $838-852$.

Rogers, E.M., 1983. Diffusion of Innovations. New York: Free Press

UNESCO, 2008. Reactive Monitoring Mission to the Town of Luang Prabang World Heritage Property Lao People's Democratic Republic. Quebec City: Canada.

UNESCO, 2012. Mobile learning for teachers in Asia: Exploring the potential of mobile technologies to support teachers and improve practice. France: Paris.

Venkatesh, V., Morris, M.G., Davis, G.B., and Davis, F.D., 2003. User acceptance of information technology: toward a unified view. MIS Quarterly, 27(3), 425-478.

World Bank, 2011. Lao PDR now a lower-middle income economy. The World Bank. Accessed September $8^{\text {th }}, 2012$ at http://go.worldbank.org/KLH78W0VX0

Yamaguchi, S.Y., Takada, J., Ooka, N. and Kawaguchi, Y., 2006. Application of Information and Communication Technology to Promote Sustainable Development. A Case Study: Town of Luang Prabang, Lao PDR. In $42^{\text {nd }}$ Conference of International Society of City and Regional Planners (Turkey, Istanbul, September 14 - 18, 2006) 